\title{
POLICE STRESS AND TEACHIER STRESS AT WORK AND AT HOME
}

\author{
ROBERT T. Sigler \\ Department of Criminal Justice \\ University of Alabama \\ Tuscaloosa, Alabama 35487-0320
}

\author{
Charles Norton Wilson \\ Department of Criminal Justice \\ University of Alabama \\ Tuscaloosa, Alabama 35487-0320
}

\author{
ZaCk Allen \\ Center for Political Studies \\ University of Michigan \\ Ann Arbor, Michigan 48109
}

\begin{abstract}
This study compared police officers and teachers in three communities-which varied in size, geographical location, and economic base-for differences in perceived occupational stress and for differences in the patterns of perceived job stress, perceived nonjob stress, and both perceived job and life stressors. For police officers, higher levels of job stress were associated with higher levels on measures of perceived job stressors. This relationship varied from city to city, with the relationship holding for the city in which both police operations and school operations were relatively normal, with no difference between police and teachers in the city in which the school administration was in conflict with its employees, and with a reversal in the city in which the police administration was noted for its excellent management skills.
\end{abstract}

While initial interest in stress and related factors which influence employee performance focused on teachers, medical personnel, and the helping professions, a substantial body of information has emerged from studies of public employees. These findings have fostered continuing interest in this area, which has generated research in criminal justice. Studies have been conducted in all fields of criminal justice, but they have been more common in law enforcement (Hageman, 1982; Kroes, Margolis, and Hurrell, 1974; Stotland, Pendleton, and Schwartz, 1989; Terry, 1981; Violanti, 1983; Maslach and Johnson, 1979; Violanti, Vena, and Marshall, 1986), corrections (Poole and Regoli, 1980; Dignam, Barrera, and West, 1986; Cullen, Link, Wolfe, and Frank, 1985), and probation and 
parole (Laningham. Taber. and Dimants, 1966; Whitehead, 1984: 1986; 1987: Whitehead and Lindquist 1985). These studies tend to indicate that criminal justice personnel do experience stress and that this stress does reduce job performance.

Police work involves a number of activities and situations which are by their nature stressproducing (Kroes, 1985). These range from the power inherent in police work to the risk to personal safety that police officers must anticipate even though they are unlikely to be exposed to great danger. The fact that they have a great deal of authority, are empowered to use deadly force, and must anticipate personal harm can induce stress (Ellison and Genz, 1983). The police are expected to exercise discretion effectively. They must make decisions (some of which are critical and some of which are likely to create hostility) with little time for deliberation.

Police officers continuously must anticipate personal physical harm. While most police officers will complete their careers and retire without experiencing a life-threatening crisis (Kirkham and Wollan, 1980), heginning with initial training, officers are prepared to anticipate crises and personal harm (Bayley, 1976). The police officer constantly faces situations which observation and experience indicate are safe but which, during training and in stated departmental policies and recommended procedures, have been defined as potentially dangerous (Cullen, Link. Travis, and Lemming, 1983). Police officers must confront personal violence and its consequences as they investigate crime scenes, traffic accidents, and domestic disturbances. These encounters have been identified as stressors in the law enforcement environment (Alkus and Padesky, 1983; Kroes and Hurrell, 1975; Levitov and Thompson, 1981). Police officers rate violence at high levels when evaluating stressors in their environment (Ellison, Cross, and Genz, 1980). They perceive exposure to violence as having an increasing impact as the form of the violence being rated moves from abusive language to processing a case in which the victim has been sexually abused. Incidents in which the police are targets of violence were rated at higher levels than all other stressors (Sewell. 1983).

The competitive advantage law breakers have in the justice system is a source of stress for police officers. An officer must cope with the demand of the public and with official pressure to deal eflectively with law breakers while obeying a set of constitutional restraints most police officers perceive as unfair (Ellison and Genz, 1983; Kroes, 1985). Police officers experience stress because they are often caught between the courts and the public. They must capture the law breakers: at the same time they must adhere to a mandate and a professional obligation to enforce the law as it has been enacted. This situation is aggravated when they are urged to use their discretion when processing high-status persons. Police officers do receive very direct pressure to engage in differential enforcement of the law based on political considerations (Terry, 1981).

Police officers must deal with a negative public image (Symonds, 1970; 1972). Ordinary citizens frequently avoid association with them, and some individuals verbally assault police officers because of the widespread negative perceptions of the police. At times police officers feel that they are accepted only by offenders. It is possible that the high degree of group identity and association observed among police officers can be attributed to rejection by others rather than to the personal preferences of police officers.

The administration and structure of police organizations themselves have been found to be a primary source of stress for police officers. The stress-producing characteristics of police organizations include: (1) leaders who are products of closed promotional systems, (2) limited mobility and promotional opportunity, (3) traditionally conservative administrative structures, (4) limited training. equipment, financial resources, and salaries. and (5) unclear policies for rewards. promotions, and career development (Kroes, Margolis, and Hurrell. 1974).

Support for the assertion that these factors produce stress in police officers can be found in a series of studies indicating that police officers experience higher levels of stress (symptoms) than other occupational groups 
or the general public. Several studies have found that police officers exhibit a high rate of stress-related illness. Studies of mortality by occupation indicate that police officers experience relatively higher rates than the general public of heart attacks and diabetes and have an increased mortality risk from cancer, particularly for cancers of the colon and liver (Guralnick, 1963; Milham, 1976; Violanti, Vena, and Marshall, 1986). Behavioral symptoms of stress also have been found to be more prevalent among police officers (Maslach and Johnson, 1979). When compared with other groups, police officers have relatively high rates of suicide, alcoholism, and divorce (Terry, 1981; Diviner, Kroeker, Miller, and Reynolds, 1975; Heiman, 1975).

Studies that have examined the actual presence of stressors indicate that police officers experience high levels of stressor activity in their work environments. Hageman (1982) found that a number of situational factors were related to stress for rookie police officers. Stress was linked to: (1) risk of harm, (2) work factors, (3) peer culture, (4) conflict with role expectations held by nonpolice figures (such as family, prosecutors, and probation officers) in the rookies' environment, (5) expectations held by coworkers and supervisors, as well as factors that were not specifically jobrelated, such as health and diet. Stress in police officers has also been found to be linked to specific justice-system sources, such as a perception of the judicial system as structured to favor law breakers and hinder police officers as they do their job (Ellison and Genz, 1983).

A number of studies have examined the nature of stress in police work and secondary pathologies linked to stress, such as suicide, divorce, and illness; however, only a limited attempt has been made to compare the presence of stress and job-related sources experienced by police officers with those experienced by other occupational groups. While most scholars support the contention that police officers experience high levels of stress, support for that position is not universal (Malloy and Mays, 1984). These authors have suggested a different model and line of research. The present study sought to address these issues by comparing stress reported by police officers with stress reported by teachers in a number of differing settings.

Teachers are an appropriate comparison group because they consistently have been identified as a group experiencing high stress at work. There is extensive documentation of the presence of stress for teachers hecause when stress/burnout was first identified by mental health workers as a pathology, it was referred to as a condition observed in medical workers, helping professions, and teachers (Hall, 1979). Thus, many of the initial studies evaluating stress focused on teachers.

Like police officers, teachers experience conflicting expectations for job performance (Alley, 1980; Hodge and Marker, 1978). They are expected to accomplish their tasks with limited resources (Hodge and Marker, 1978), and they receive relatively poor salaries (Grossnickle, 1980). Factors identified as primary sources of stress for teachers include relationships with colleagues, administrative staff, clerical staff, and students; complex communication needs related to the wide range of skills of students; and the tasks of dealing with inattentive students, discussing discipline procedures with students, and listening to students" personal and academic problems (Hodge and Marker, 1978). Several additional occupational factors have been cited, including the need to discipline students (Swick and Hanley, 1980), daily abuse from students and parents (Grossnickle, 1980), pressures to conform to differing philosophies of education (Hodge and Marker, 1978), and the high standards for teacher conformity to social values (Grossnickle, 1980). Teachers, like police officers, demonstrate higher incidence of pathologies associated with stress, such as physical incapacity (Cardinell, 1980) and some forms of cancer (Kossack and Woods, 1980). Thus, teachers would appear to be an appropriate comparison group for estimating the relative levels of occupational stress experienced by police officers.

\section{METHODOLOGY}

This study is a replication of an earlier one that examined patterns of stress experienced 
by police officers and teachers (Sigler and Wilson, 1988). The original data were collected at a single site in the northeastern United States. The analysis of that dataset indicated that police officers experienced greater stress from job-related sources than teachers. The instrument was then administered at two additional sites to permit an evaluation of the stability of the relationship observed. The combined dataset was composed of the responses to a structured questioniraire which was distributed in police stations and schools in these three sites. All teachers and police officers in (1) a small northeastern bedroom community, (2) a medium-sized southern town with a technical base, and (3) an older urban area in a southern suburban county were included in the study. The research sought to determine if police officers experience greater stress than teachers and if there were differences in the patterns of stressors within each group.

\section{Variables}

In this study, stress was defined as the perceived imbalance between societal demands and individual perceived response capability in which failure to meet the demands produces dysfunction that results in reduced performance. This dysfunction is expressed or accompanied by a number of physiological symptoms, such as headaches and minor physical ailments. Stress was measured on two scales composed of a list of these physiological symptoms generated from a comprehensive review of various diagnostic manuals, treatment manuals, and related literature. One scale measured the perceived presence of these symptoms on the job (job stress). The second scale measured the subject's perception of these symptoms off of the job (life stress). Subject scores were the numbers of symptoms subjects indicated that they experienced frequently.

Stressors are defined as those life events which are likcly to cause stress. General life stressors were measured on a scale listing twenty-six events identified in the literature as causing stress (life stressors). This scale was adapted from the Holmes and Rahe So- cial Readjustment Scale (Holmes and Rahe, 1967). Subject scores were the numbers of yes responses. A second set of items focused on stressors associated with work (job stressors). This scale was composed of fourteen items measured on a 5-point ( 0 to 4 ) scale. Subject scores were the sums of the scores for the items. A subscale measuring the presence of administrative problems was constructed from the five items in the job stressor scale which referenced problenis associated with administration of the organization (administrative stressors). Examples of items from these scales can be found in the appendix.

Job dissatisfaction was defined as the extent to which employees were dissatisfied with their employment, and it was of interest in this study as a possible stressor. It was measured with a 30-item Likert-type scale. Following item analysis using interquartile $t$ 's, six nonpredicting items were dropped, producing a 24-item scale.

Additional scales measured consumption of alcoholic beverages, use of medication, and smoking. In addition, data were collected for a number of demographic variables, physical-fitness activities, and participation in stressmanagement activities.

\section{Hypothesis}

This replication retested the belief that police officers experience higher levels of stress than other occupational groups by comparing police officers with another high-stress occupational group, teachers. In an earlier study, this hypothesis was supported, and a strong relationship was discovered between on-thejob stress and type of stressors, with police stress found to be more closely related to job stressors than was teacher stress (Sigler and Wilson, 1988). This study sought to examine the extent to which the earlier findings could be generalized to other settings.

In the prior study job stressors and administrative stressors appeared to be related to stress. To explore this relationship further, the additional sites were selected partly on the basis of differing management configurations. To clarify any relationships which might occur, a number of control variables were 
evaluated for their impact on stress and occupation.

\section{Setting}

The first city (city 1) is located in the northern section of a southern state. It has a technical economic base with a strong government presence and a private research and development presence. The nature of the city's research activities has made its population somewhat transient, resulting in a mix of ethnic, political, and religious groups. Clear socioeconomic areas do not exist, and poor and rich neighborhoods are scattered throughout the city. The population is approximately 165,800 , and it has been growing at a steady pace, with corresponding growth in the police department and in the school system. There are five high schools with a total of 453 teachers and administrators. The police department has 242 sworn officers and is recognized by law enforcement professionals as a progressive, exceptionally well managed department. The department's reputation for good management was one factor which influenced the decision to collect data at that site.

The second city (city 2) is one of the oldest cities in the South. It has clearly established racial and socioeconomic neighborhoods, including "suburban communities" outside of its boundaries. It borders the Gulf of Mexico, and it is a major shipping and ship-building center with both light and heavy industry in its economic base. It has a population of approximately 125,000 . There is no city school system. The county provides all public education and serves the city population with four schools, which have a total of 424 teachers and administrators. Although the school district lines do not exactly correspond with the city limits, the match is sufficiently close to permit an assumption that the teachers at these four schools and the city police officers serve the same population. The police department has 345 sworn officers. The city and its institutions are relatively stable. The public school system is presently experiencing some turmoil. Teachers and administrators appear to be in conflict over a number of issues. This situation was not known at the time the city was chosen as a site for data collection; it became apparent during the data-collection process. The research assistant collecting the data was approached privately by teachers in two different schools with offers to tell him about the severity of working conditions in the school system.

The third setting (city 3 ) is a small suburban bedroom community in the Northeast, which borders a larger urban area. It has a population of approximately 31,000 people, and it can be characterized as a predominantly upper-middle-class to upper-class community. Its public education needs are served by one public high school, which has an enrollment of 900 students and has eighty teachers and administrators. The police department is staffed by thirty-two full-time employees.

\section{Population and Sample}

The sample population for this study was defined as the sworn officers and administrators of the police departments and the teachers and administrators of the high schools in the three cities. Survey instruments were administered to all members of the defined population. Of the police department respondents, 190 of the 619 returned their questionnaires ( 28.4 percent), and 270 of the 957 school system respondents returned theirs (28.2 percent). All of the questionnaires were relatively complete and were included in the analysis. Response rates ranged from a low of 17 percent of the teachers in the city which was experiencing difficulties in the schools to a high of 78 percent of the police in the city in which one of the researchers was a police officer. Demographically, the sample was similar to the population from which it was drawn. For variables such as mean salary, mean length of time in the field, and length of time in the current position, accurate figurcs were not available; however, the sample means approximated the estimated means provided by the agencies. Although the sample appears to have been demographically similar to the population, it is possible that, 
given the focus of the study, there was a selective bias. If so, it is likely that those who experienced the most stress would have been most likely to respond. Such a bias would not necessarily produce invalid results; however. the findings should be interpreted with caution. Conservative conventional standards regarding the use of significance were observed throughout the analysis.

\section{Data Collection}

The questionnaires were delivered to the subjects in their work places. In the case of the teachers, they were placed in the individual mail boxes maintained by the schools. The questionnaires were hand-delivered to the police officiers during roll call or at their work stations. In each setting, a clearly labeled collection box was established in an area identified as line-staff territory. The box was sealed and had a slot for receiving the instruments. The instructions which accompanied the questionnaires directed subjects to complete them at their leisure and to deposit the completed instruments in the box. A researcher collected the questionnaires at the end of a two-week period. Three questionnaires from teachers in city 3 were mailed directly to the office of the reseachers.

\section{FINDINGS}

The data were analyzed using the Statistical Package for the Social Sciences. In addition to hypothesis-testing procedures, all possible relationships with the perceived stress and job satisfaction measures were examined. The results reported here are limited to differences between police officers and teachers for the demographic variables and the stress-related variables. The distribution of each of the interval variables was evaluated and was found to approximate a normal curve. All measures for skewness and kurtosis were less than \pm 1 .

The two occupational groups differed on several demographic variables: age, education, sex, salary, and length of time employed in the field and in their current posi- tions. While approximately 65 percent of the teacher sample was female, only about 8 percent of the respondents in the police officer sample were female. Teachers were found to have more education than police ofticers. However, it should be noted that, for this population. all but about $1+$ percent of the police officers had attended college and 28 percent had earned at least a bachelor's degree. Teachers were more likely to be religiousiy active $(p$ ) for chi square $=.0001)$ and more likely to associate with people other than their colleagues $(p$ for chi square $=.0005)$. Police officers were more likely to have been subjects of disciplinary action $(p$ for chi square $<.00011$.

Age, salary, and the employment history variables were found to be interrelated $(r>$ .3826 and $p<.001$ for all comparisons). Teachers earned more money $(p)<.0001, t$ $=4.23)$. were older $(p<.0001 . t=12.22)$. had worked longer in their tield $(p<.0001$. $t=8.27$ ), and had worked longer in their present positions $(p)=.0001, t=6.46)$. This probably can be attributed to the difference in career paths for teachers and police officers. Police officers tend to leave police work after twenty years, whereas teachers remain until actual retirement age. which influenees age. length of employment, and salary factors. There were no significant differences among the cities for the demographic variables. with the exception of marital status and salary. Salaries were higher in city $3, F=$ $16.741, p<.0001$ ) by approximately $\$ 5,000$. The respondents from the old southern city were more likely to be single people who had never married and less likely to be married at present than those from the other cities $(p)$ for chi square $=.0297$ ). The subjects in city 2 were more likely to associate with their colleagues ( $p$ for chi square - .0002). There were no significant differences among the cities for any of the stress or stressor variables.

Mixed support was found for the hypothesis. For the total sample the relationships between job type and both perceived job stress and perceived life stress were not significant. However, there were differing patterns for the individual cities ( see Table 1). In the city in which the police department and the school 


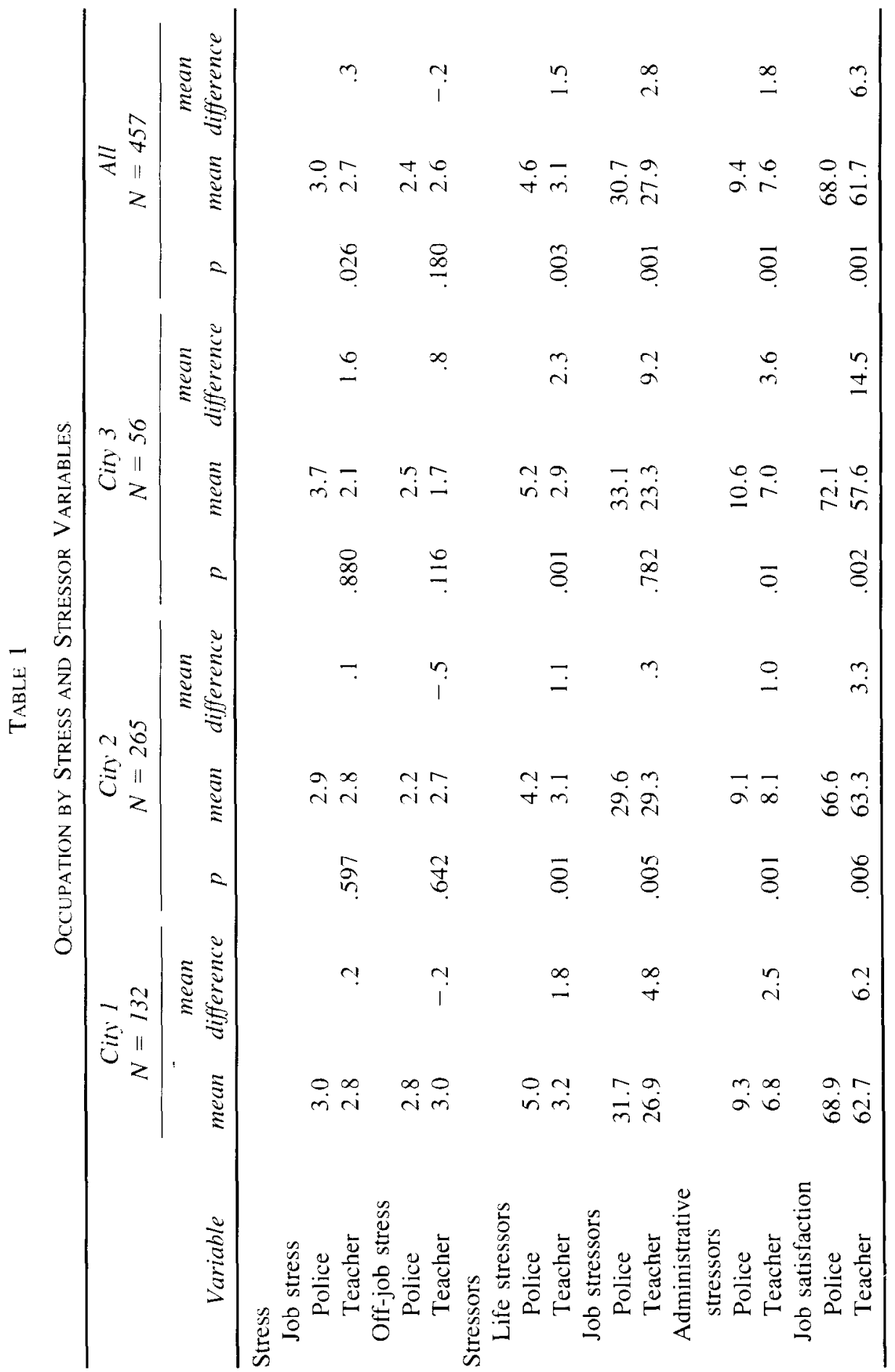


system were "normal" (city 3), police officers experienced more job stress than teachers. In the city in which the police department was recognized for the excellence of its operations (city 1), there was virtually no difference in reported job stress. In the city in which the school system was experiencing exceptional conflict between the teachers and the administration (city 2), there was also virtually no difference in reported job stress between teachers and police. It should be noted that police officers reported higher levels of stressors of all types than teachers for all comparisons except for the levels of job stressors reported for city 2 . That is, in city 2 the teachers reported about the same level of stressful events in the working environment as police officers reported.

The examination of the relationship between the stressors and stress for the two occupations began with an examination of the relationships among all stress and stressor variables. A comparison of perceived on-thejob stress and perceived off-the-job stress with the various stressors indicated that these variables tended to be interrelated; all comparisons were significant except for the relationship between life stress and administrative stressors. When these relationships were examined for job type and city, the patterns remained fairly stable except for city 3 . For city 3 , job stress and life stress were not significantly related to job stressors and administrative stressors. None of the relationships between the stress variables and the demographic variables were found to be significant.

\section{DISCUSSION}

There appears to be support for the contention that perceived job stress is related to perceived job stressor levels and for the con- tention that police experience higher levels of job stress than teachers. In city 3, the police department and the school system appear to have been operating normally. In this setting, police officers demonstrated higher levels of job stress related to job stressors and administrative stressors than did teachers. In city 2 , the police department appears to have been operating normally while the school system appears to have been experiencing difficulty that created conflict between managers and teachers. In this setting teachers and police officers demonstrated similar levels of job stress related to perceived job stressors. In city 1 , the police department was recognized for the competence and innovative skills of its managers, and the school system appears to have been operating normally. In this setting. teachers demonstrated higher levels of job stress related to job stressors than did police officers.

Stress-related illnesses and reduced performance are expensive consequences for an agency, both in terms of operating costs and in terms of damage to employees; therefore. it is important to understand the relationships among job stressors, administrative stressors, and job stress. The present line of research indicates that stress for police officers is related to their work experiences and that different levels of stress exist in different management environments. At the next stage, research should focus on the development and dynamics of stress in police officers and on the specific factors that are related to the development and functioning of stress in the work environment. The discovery of the factors or processes that lead to elevated stress will provide a broader basis for understanding stress and will give police managers information needed to redesign work tasks, to develop intervention and treatment programs, or to develop coping skills for dealing with the factors or processes that cause stress. 


\section{APPENDIX}

This section deals with gencral life stress. If you have experienced any of these within the past 6 months, please check the yes box.

1. Death of a spouse

2. Divorce

3. Marital separation

4. Death of any family member

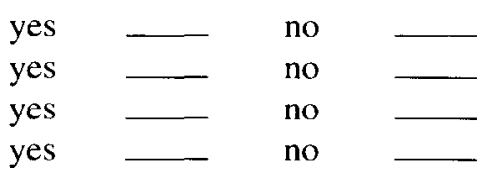

This section deals with on the job stress. If you have experienced any of these within the past 6 months, please check the yes box.

21. Promotion

22. Promotion of a close friend

23. Court testimony

24. Increased recognition for good work

25. Experiencing transfer or retirement of friend

26. Change in hours on the job

27. Target of a job related lawsuit

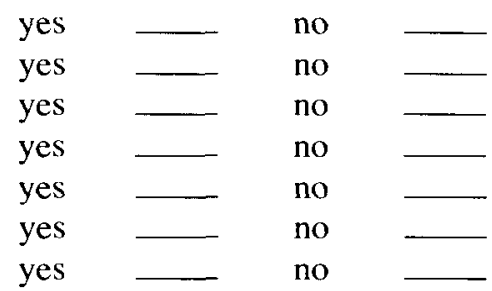

How often have you experienced each of the following while at work during the past month?

86. Fecling faint

87. Headaches

88. Loss of appetite

89. Nausea

90. Feeling tense

91. Backaches

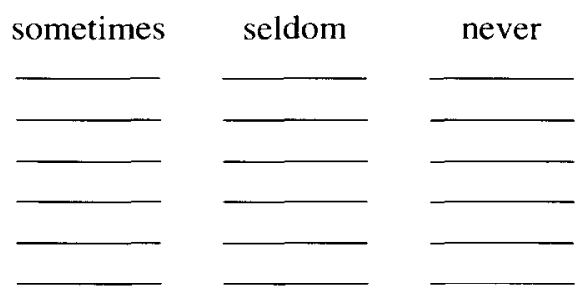

How often have you experienced each of the following while not at work during the last month?

100. Feeling faint

101. Headaches

102. Loss of appetite

103. Nausea

104. Feeling tense

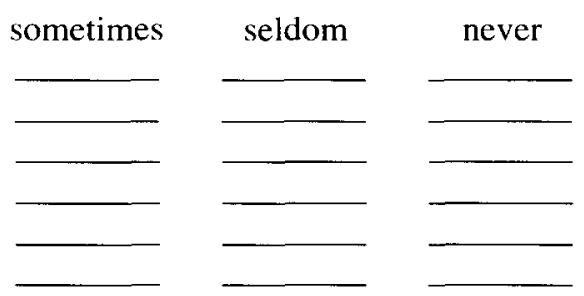

105. Backaches 


\section{REFERENCES}

Alkus, S., and Padesky, C. (1983). Special problems of police officers: Stress-related issues and interventions. Couns Psych 11(2): 55--64

Alley, R. (1980). Stress and the professional educator. Action in Teacher Education 2: 1-4.

Bayley, D. H. (1976). Forces of order. Berkeley: University of California Press.

Cardincll. L. (1980). Teacher burnout: An analysis. Action in Teacher Education 2: 9-15.

Cohen, J., and Cohen, P. (1975). Applied multiple regression/correlation analysis for the behavioral sciences. Hillsdale. NJ: Lawrence Erlbaum Associates.

Cullen, F.; Link. B. G.; Travis. L..; and Lemming, T. (1983). Paradox in policing: A note on perceptions. $J$ Police Sci Adm 11; 457-62.

Cullen, F.; Link, B. G.; Wolfe, N. T.; and Frank, J (1985). The social dimensions of correctional officer stress. Justice Quarterly 2: 505-33.

Dignam. J. T.; Barrera, M., Jr.: and West, S. G. (1986). Occupational stress, social support, and burnout among correctional officers. Am J Community Psychol 14: $177-93$.

Diviner, J.; Kroeker, M.: Miller, L.: and Reynolds, W. (1975). Divoree, an occupational hazard. Police Chief 42: $48-53$.

Ellison, K. W.; Cross, J. P.; and Genz, J. L. (1980) Training in stress management. Police Chief 42: 27 31

Ellison, K.. and Genz. J. (1983). Stress and the police officer. Springfield. IL: Charles Thomas.

Grossnickle, D. (1980). Teacher burnout: Will talking about it help! (Clearing $H$ 54(17-18): $16-26$.

Guralnick, L. (1963). Mortality by occupation and cause of death. U.S. Public Health Scrvice. Vital statistics, special report, vol. \#53. Washington, DC: U.S. Government Printing Office.

Hageman, M. J. (1982). Responses of rookic police officers to stress. I Police Si Adm 10: 235-43.

Hall, R. (1979). The professional burnout syndrome Psychiat Opin 15: 12-17.

Heiman, M. F. (1975). Police suicide. I Police Sci Adm 3: $267-73$.

Hodge, J., and Marker, P. (1978). Assessing teacher stress: A beneficial task for the administrators. Am Sec Educ 8: 49-57.

Holmes, T. H., and Rahe, R. H. (1967). Social readjustment rating scale. Psychosomatic Medicine 11 213-18.

Kirkhan, G., and Wollan, L. (1980). Introductien "o law enforcement. New York: Harper \& Row.

Kossack, S. and Woods, S. (1980). Teacher burnout: Diagnosis, prevention, and remediation. Action in Teacher Education 2(4): 29-36

Kroes, W. H. (1985). Society's bictims-The police. Springfield, IL: Charles $\mathrm{C}$. Thomas

Kroes, W., and Hurrell, J. (eds.). (1975). Job stress and the police officer: Identifing stress reduction techniques. Washington, DC: Government Printing Office.

Kroes, W.: Margolis, B.: and Hurrell, J. (1974). Job stress in police administrators. $J$ Police Sct Adm 2: $381-87$.

Laningham, D.; Taber, M.; and Dimants, R. (1966). How adult probation officers view their job responsibilities. Crime Detin 12:97-108.

Levitov, J. E., and Thompson. B. (1981). Stress and counseling needs of police officers. Counsel Educ \& Super. 20: $163-68$.

Malloy, T. Y., and Mays, G. L. (1984). The police stress hypothesis: A critical evaluation. Crim Jast B 11: $197-224$.

Maslach, C. and Johnson, J. (1979). Burned out cops and their families. Prychol Tod 13(5) 59-62.

Milham. S. (1976). Occupational mortality in Washington state 1950-1959. NOISH publication no. 83. 116. Washington, DC: U.S. Government Printing Office.

Poole, E. D., and Regoli, R. M. (1980). Role stress, custody orientation, and disciplinary action. Crim 18: $215-26$

Sewell. J. D. (1983). The development of a critical life events scale for law enforcement. I Police Sci Adm 11: $109-10$.

Sigler, R. T., and Wilson, C. N. (1988). Stress in the work place: Comparing police stress with teacher stress. J Police Sci Adm 16: 151-62.

Stotland, E.; Pendleton, M.; and Schwartz, R. (1989). Police stress, time on the job. and strain. I Crim . Iust 17: $5.5-60$.

Swick, K., and Hanley, P. (1980). Stress and classroom teaching. Washington, DC.: National Education Association.

Symonds, M. (1970). Emotional hazards of police work. Am J Psvchoanal 30: 155-60).

(1972). Policemen and policework: A psychodynamic understanding. Am J Psychoanal 32: 163 69.

Terry, W. (1981). Police stresis: The empirical evidence, J Police Sici Adm 9: 61-75.

Violanti, J. (1983). Stress patterns in police work. $J$ Police Sci Adm 11: 211-16.

_ Vena, J., and Marshall, J. (1986). Disease risk and mortality among police officers: New evidence and contributing factors. I Police Sil Adm 14: 1723.

Whitehead, J. T. (1986). Job burnout and job satisfaction among probation managers. J Crim Just 14:2535 .

- (1987). Probation officer job burnout: A test of two theories. J Crim Just 15: $1-16$

(1984). Probation mission reform: Implications for the forgotten actor: The probation officer. Criminal Justice $R$ 9: 15-21.

and Lindquist. C. (198.5). Job stress and burnout among probation/parole officers: Perceptions and causal factors. InI $J$ Offender Ther \& Comp Criminology 29: 109-19. 